\title{
ANALISIS PENGETAHUAN LANSIA TERHADAP PEMENUHAN PERSONAL HYGIENE DI PUSKESMAS WERDHI AGUNG
}

\author{
Sitti Rahma Soleman, Fernando M. Mongkau, Ida Bagus Ekasuryadinata \\ 1,2 Dosen Program Studi Ilmu Keperawatan, Fakultas Ilmu Kesehatan, Institut Kesehatan dan Teknologi \\ Graha Medika \\ ${ }^{3}$ Mahasiswa Program Studi Ilmu Keperawatan, Fakultas Ilmu Kesehatan, Institut Kesehatan dan \\ Teknologi Graha Medika \\ Alamat Korespondensi: sittirahmasoleman@gmail.com
}

\begin{abstract}
Abstrak
Menurut WHO bahwa status lansia tertinggi berada di daratan ASIA, jumlah yang di prediksi sebagai angka tertinggi di dunia yaitu sebesar 400 juta penduduk atau $1 / 2$ dari jumlah lansia di dunia. Negara Indonesia menjadi salah satu wilayah bagian ASIA yang mengalami peningkatan jumlah lansia sebesar $0,89 \%$. Banyaknya jumlah lansia di indonesia merupakan salah satu dampak dari peningkatan usia harapan hidup masyarakat indonesia. Penelitian ini merupakan jenis kuantitatif dengan pendekatan deskriptif menggunakan metode cross-sectional. Dilaksanakan pada bulan juni-juli 2020 di puskesmas Werdhi Agung, dengan jumlah populasi sebanyak 158 orang lansia, dan sampel sebanyak 32 dengan metode sampling Purposive Sampling. Penelitian ini dilakukan untuk mengetahui keterkaitan antara tingkat pengetahuan lansia terhadap personal hygiene. Hasil penelitian mengemukakan bahwa teradapat keterkaitan hubungan yang signifikan antara pengetahuan lansia dengan perilaku personal hygiene yang dilakukan oleh lansia. Rendahnya pengetahuan lansia terhadap perilaku personal hygiene di wilayah kerja Puskesmas Werdhi Agung menjadi penyebab utama lansia belum memiliki status kesehatan dan kesejahteraan yang cukup. Pengetahuan menjadi salah satu hal utama dari beberapa faktor yang dapat merubah dan memotivasi perilaku kesehatan, sedangkan pengetahuan dipengaruhi oleh usia, dan pendidikan.
\end{abstract}

Kata Kunci: Pengetahuan, Personal Hygiene

\begin{abstract}
According to WHO, the highest status of elderly is in mainland ASIA, the number predicted to be the highest in the world, which is 400 million people or $1 / 2$ of the world's elderly. Indonesia is one of the ASIA regions where the number of elderly people has increased by $0.89 \%$. A large number of elderly people in Indonesia is one of the impacts of increasing the life expectancy of the Indonesian people. This research is a quantitative type with a descriptive approach using cross-sectional methods. Held in June-July 2020 at the Werdhi Agung Puskesmas, with a population of 158 elderly people, and a sample of 32 with purposive sampling method. This research was conducted to determine the relationship between the level of knowledge of the elderly with personal hygiene. The results showed that there was a significant relationship between the knowledge of the elderly and the personal hygiene behavior performed by the elderly. The low knowledge of the elderly about personal hygiene behavior in the working area of Werdhi Agung Community Health Center is the main cause of the elderly who do not have sufficient health and welfare status. Knowledge is one of the main factors of several factors that can change and motivate health behavior, while knowledge is influenced by age and education.
\end{abstract}

Keywords: Knowledge, Personal Hygiene 


\section{PENDAHULUAN}

Keberhasilan terbesar sektor kebijakan kesehatan masyarakat yaitu harapan hidup manusia yang terus meningkat. Tahun 2025 diperkirakan terdapat 1,2 miliar penduduk dengan status lansia, 500 juta diantaranya rentan usia 60 tahun dan lainnya pada rentan usia di atas 60 tahun. Pada tahun 2019 peningkatan jumlah lansia hingga $8,1 \%$ dibandingkan pada tahun 2018, (KEMKES RI, 2019).

Menurut WHO bahwa status lansia tertinggi berada di daratan ASIA, jumlah yang di prediksi sebagai angka tertinggi di dunia yaitu sebesar 400 juta penduduk atau $1 / 2$ dari jumlah lansia di dunia (WHO, 2018). Negara Indonesia menjadi salah satu wilayah bagian ASIA yang mengalami peningkatan jumlah lansia sebesar 0,89\% di tahun 2019 (KEMKES RI, 2019).

Banyaknya jumlah lansia di indonesia merupakan salah satu dampak dari peningkatan usia harapan hidup masyarakat indonesia, hal tersebut menjadi hal yang baik bagi kebijakan kesehatan di indonesia saat ini, namun hal tersebut juga harus di sertakan dengan pelayanan kesehatan yang maksimal. Penuaan pada manusia merupakan suatu kodrat yang pasti dialami. Usia tua merupakan fase terjadinya disfungsi biologis manusia yang ditandai dengan timbulnya keriput pada kulit, rambut yang telah beruban, gigi yang telah tanggal, mata yang telah rabun (Sudarsih \& Sandika, 2017).

Tua merupakan keadaan tubuh manusia yang secara berlahan akan mengalami disfungsi jaringan tubuh. Dalam prosesnya orang-orang yang mengalami masa tua berlahan memiliki daya tahan tubuh yang berkurang sehingga rentan terhadap berbagai infeksi serta kerusakan sel metabolik (Darmojo \& Martono, 2018). Lansia adalah orang-orang yang memiliki usia yang $\geq 60$ tahun (DEPKES RI, 2015).

Bertambahnya jumlah penduduk yang berstatus lansia berbanding lurus dengan permasalahan kesehatan dan kesejahteraan sosial yang timbul dikalangan lansia (Notoatmodjo, 2014). Faktor personal Hygiene menjadi slah satu permasalahan bagi penduduk lansia. Personal Hygiene bagi penduduk lansia adalah bentuk perawatan untuk menjaga kebersihan diri yang menjadi langkah untuk mencapai dan menjaga kesehatan tubuh sehingga terhindar dari risiko terserang penyakit (Saryono \& Widianti, 2015).

Pentingnya tingkat pemahaman terkait personal hygiene sangat di butuhkan untuk meningkatkan derajat kesehatan pada masyarakat khususnya bagi lansia. Fokus lansia terhadap personal hygiene sangat kurang. Kerja sama lintas sektor pemerintah dan antar masyarakat sangat di harapkan untuk mendorong tatalaksana dan pengetahuan lansia terkait personal hygiene (Yuni, 2015).

Ditengah perkembangan zaman saat ini personal hygiene dipandang sangat penting bagi lansi untuk meningkatkan dan menjaga kualitas kesehatannya, personal hygiene yang dapat diberikan kepada lansia bergantung pada kebutuhan perawatan untuk memenuhi kenyamanannya (Iswantiah, 2016). Kurangnya pengetahuan lansia menjadi faktor utama terhadap kurangnya kualitas personal hygiene pada lansia, pendampingan dan perhatian keluarga serta lingkungan menjadi hal kedua yang mempengaruhi kebersihan diri lansia (Akay \& Rumend, 2015).

Tingkat usia masyarakat yang tergolong dalam usia lansi saat ini masih memiliki pengetahuan yang rendah, 
sedangkan pengetahuan dan perilaku lansia terkait personal hygiene masih kurang baik, sehingga hal tersebut dapat menjadi faktor utama rendahnya derajat kesehatan dan kesejahteraan lansia (Erdayanti \& Kartinah, 2016). Pengetahuan lansia sangat erat kaitannya terhadap perilaku personal hygiene bagi setiap lansia, pengetahuan lansia menjadi faktor utama terlaksananya personal hygiene pada setiap lansia (Widanar, 2020). Saat ini jumlah lansia di provinsi sulawesi utara telah tercatat sebanyak $9,05 \%$ pada tahun 2019 dari jumlah penduduk sebanyak 2.621.923 jiwa, estimasi tertinggi pada Kabupaten Bolaang Mongondow sebesar 61.180 jiwa (Badan Pusat Statistik SULUT , 2019). Dan telah mengalami peningkatan menjadi $12,08 \%$ pada tahun 2020 (Barometer, 2021).

Observasi pendahuluan yang dilakukan di wilayah kerja puskesmas Werdhi Agung, pada bulan februari tahun 2020, terhadap 158 lansia, diketahui bahwa sebagian besar perilaku dan penata laksanaan personal hygiene belum diketahui dan belum dipahami oleh lansia tersebut, dan tidak memahami terkait pentingnya kebersihan diri di usia tua.

\section{METODE PENELITIAN}

Penelitian ini merupakan jenis kuantitatif dengan pendekatan deskriptif menggunakan metode cross-sectional, pengukuran variabel pada responden di tekankan hanya sekali dalam satu waktu (Nursalam, 2016). Penelitian ini dilaksanakan pada bulan juni-juli 2020 di puskesmas Werdhi Agung, dengan jumlah populasi sebanyak 158 orang lansia, dengan jumlah sampel sebanyak 32 orang, yang di tentukan berdasarkan metode sampling Purposive Sampling. Penelitian ini dilakukan untuk mengetahui keterkaitan antra tingkat pengetahuan lansia terhadap personal hygiene. Pengambilan data pada responden dimulai dengan memintai persetujuan dari responden dan keluarga responden terlebih dahulu, kemudian apabila responden bersedia, dilanjutkan dengan proses wawancara, dan memberi cendera mata sebagai ucapan terimakasih kepada responden.

\section{HASIL PENELITIAN}

Data karakteristik pribadi responden yang terdiri dari usia, jenis kelamin dan pendidikan terakhir.

Tabel 1. Distribusi Karakteristik Responden Penelitian

\begin{tabular}{llll}
\hline Variabel & Kategori & $\mathrm{n}$ & $\%$ \\
\hline Usia & $60-74$ & 21 & 65,6 \\
& $75-90$ & 11 & 34,4 \\
\hline Jenis & Laki-laki & 17 & 53,1 \\
Kelamin & Perempuan & 15 & 46,9 \\
\hline Pendidikan & SMP & 20 & 62,5 \\
Terakhir & SMA & 12 & 37,5 \\
\hline
\end{tabular}

Uraian pada tabel 1. Diketahui bahwa lansia yang berjenis kelamin lakilaki lebih dominan di banding dengan lansia perempuan. Adapun tingkat pendidikan lansia masih tergolong rendah, hal tersebut dapat diketahui bahwa pendidikan lansi sebagian besar berada pada tingkatan menengah pertama. 
Tabel 2. Distribusi pengetahuan lansia di puskesmas werdhi Agung

\begin{tabular}{|c|c|c|}
\hline Pengetahuan & $\mathrm{n}$ & $\%$ \\
\hline Baik & 13 & 40,6 \\
\hline Buruk & 19 & 59,4 \\
\hline Total & 32 & 100 \\
\hline
\end{tabular}

Uraian data pada tabel 2. Menunjukkan bahwa pengetahuan lansia terkait personal hygiene masih sangat rendah, hal tersebut dapat di ketahui

dengan besarnya persentase pengetahuan lansia yang masih dalam kategori buruk di wilayah kerja Puskesmas Werdhi Agung.

Tabel 3. Distribusi pemenuhan personal Hygiene pada Lansia di Puskesmas Werdhi Agung

\begin{tabular}{lcc}
\hline Personal Hygiene Lansia & $\mathrm{n}$ & $\%$ \\
\hline Baik & 15 & 46,9 \\
Kurang Baik & 17 & 53,1 \\
\hline Total & 32 & 100 \\
\hline
\end{tabular}

Data pada tabel 3. Menunjukkan bahwa perilaku personal Hygiene lansia di wilayah kerja puskesmas Werdhi Agung belum maksimal, hal tersebut dapat diketahui berdasarkan pada hasil penelitian yang menunjukkan bahwa masih tingginya proporsi lansia dengan perilaku personal hygiene yang kurang baik.
1. Analisis Bivariat

a. Analisis variabel pengetahuan dengan personal hygiene pada lansia.

Menganalisis keterkaitan antara tingkat pengetahuan lansia dengan perilaku personal hygiene lansia di wilayah kerja Puskesmas Werdhi Agung.

Tabel 4. Distribusi Pengetahuan Lansia Terhadap Pemenuhan Personal Hygiene Di Puskesmas Werdhi Agung.

\begin{tabular}{lrrrrrrrl}
\hline \multirow{3}{*}{ Pengetahuan } & \multicolumn{4}{c}{ Pemenuhan Personal Hygiene } & \multirow{2}{*}{ Jumlah } & \multirow{2}{*}{ P Value } \\
\cline { 2 - 6 } & \multicolumn{2}{c}{ Baik } & \multicolumn{3}{c}{ Kurang Baik } & & & \\
\cline { 2 - 6 } & $\mathrm{n}$ & $\%$ & $\mathrm{n}$ & $\%$ & $\mathrm{~N}$ & $\%$ & \\
\hline Baik & 11 & 34,4 & 2 & 6,2 & 13 & 40,6 & \multirow{2}{*}{0.000} \\
Buruk & 4 & 12,5 & 15 & 46,9 & 19 & 59,4 & \\
\hline Jumlah & 15 & 46,9 & 17 & 53,1 & 32 & 100,0 & \\
\hline
\end{tabular}

Uraian data pada tabel 4. Menjelaskan bahwa masih tingginya proporsi lansia yang memiliki pengetahuan yang buruk dengan perilaku personal hygiene yang masih kurang baik yaitu sebesar 46,9\%. Dibandingkan dengan lansia yang memiliki pengetahuan yang baik dan perilaku personal hygiene yang baik.

Berdasarkan hasil analisis secara statistik diketahui bahwa terdapat keterkaitan hubungan yang signifikan antara pengetahuan lansia dengan Perilaku personal hygiene yang dilakukan oleh lansia yang berada di wilayah kerja Puskesmas Werdhi Agung, dengan nilai signifikansi $(\mathrm{P}=0.000)$.

\section{PEMBAHASAN}

Berdasarkan hasil penelitian yang dilaksanakan di Puskesmas Werdhi Agung, terhadap 32 sampel responden, diketahui bahwa tingkat pengetahuan lansia masih dalam kategori buruk sedangkan perilaku personal hygiene lansia masih kurang baik. 
Hasil analisis secara statistik di temukan bahwa teradapat keterkaitan hubungan yang besar antara pengetahuan lansia dengan perilaku personal hygiene yang dilakukan oleh lansia. Rendahnya pengetahuan lansia terhadap Perilaku personal hygiene di wilayah kerja Puskesmas Werdhi Agung menjadi penyebab utama lansia belum memiliki status kesehatan dan kesejahteraan yang cukup.

Pengetahuan menjadi salah satu hal utama dari beberapa faktor yang dapat merubah dan memotivasi perilaku kesehatan, sedangkan faktor pengetahuan dipengaruhi oleh usia, dan pendidikan. Pengetahuan merupakan visualisasi dari wawasan yang dimiliki seseorang sehingga dapat merubah perilaku seseorang terkait permasalahan kesehatan yang dihadapi (Notoatmodjo, 2014).

Lansia cenderung memiliki masalah kesehatan khususnya terkait dengan personal hygiene, yang disebabkan oleh faktor berkurangnya kekuatan fisik, dan interaksi sosial antara sesama masyarakat yang lainnya (Bandiyah, 2013). Untuk meningkatkan perilaku personal hygiene dibutuhkan pengetahuan yang cukup untuk memahami proses dan tatalaksana personal hygiene yang baik dan benar. Tingkat kemampuan individu lansia untuk memahami perilaku personal hygiene sangat dipengaruhi oleh pengetahuannya (Mubarak, Iqbal, \& Chayatin, 2017).

Kurangnya pemahaman lansia terkait personal hygiene karena tidak mengerti apa yang di maksud dengan personal hygiene. Informasi yang diterima oleh lansia untuk mengetahui terkait personal hygiene masih sangat minim. Lansia hanya mengetahui aktivitas personal hygiene seadanya hanya sebatas mencuci tangan dan menggosok gigi. Perlunya tindakan langsung untuk memberi peninjauan dan edukasi pada lansia sangat penting untuk meningkatkan drajat kesehatannya (Hardono, Tohiria, Wijayanto, \& Sutrisno, 2019).

Kurangnya atau penurunan perilaku personal hygiene pada lansia disebabkan dari kurangnya pengetahuan yang dimiliki. lansia yang dengan umur lebih tua cenderung memiliki pengetahuan yang sangat minim dan tidak dapat melakukan personal hygiene dengan baik (Wawan \& Dewi, 2015).

Fenomena buruknya pelaksanaan personal hygiene pada lansia yang berpengaruh terhadap tindakan memelihara kesehatannya. Tersedianya sarana dan prasarana menjadi salah satu faktor pendukung terlaksananya perilaku personal hygiene, rendahnya tingkat jangkauan fasilitas kesehatan membatasi lansia untuk melakukan personal hygiene, (Trisani, Husodo, \& Kusumawati, 2017). Fasilitas kesehatan menjadi salah satu faktor pendorong atau memotivasi masyarakat untuk melakukan pengobatan atau menerima pelayanan kesehatan, dan memudahkan pasien dan petugas kesehatan untuk melakukan kegiatan atau program kesehatan (Sudirman, 2018).

Penurunan dan perubahan biologis lansia berpengaruh dalam memenuhi perilaku personal hygiene khususnya perubahan fisik yang kurang mampu menyesuaikan dengan kondisi lingkungan. Dukungan terhadap lansia untuk melakukan personal hygiene sangat penting untuk memberi kesehatan, kenyamanan dan keamanan. Lansia dengan keadaan yang sehat dan aman akan lebih mudah melakukan personal hygiene secara mandiri (Ranandika, Sukraandini, \& Puspita Yanti, 2020). 


\section{DAFTAR PUSTAKA}

Akay, T. W., \& Rumend, R. R. (2015). The Correlation of Family'S Knowledge With The Elderly Treatment at Home. Buletin Sariputra, 2(1), 1-6.

Badan Pusat Statistik SULUT . (2019). Pedoman Pendataan Survei Penduduk Antar Sensus 2019. Manado: Badan Pusat Statistik SULUT .

Bandiyah, S. (2013). Lanjut Usia dan Keperawatan Gerontik (1 ed.). Yogyakarta: Nuha Medika.

Barometer. (2021). Lansia diatas 10 persen, Populasi Penduduk Sulut Mеnua. Retrieved Januari 7, 2021, from https://barometer.co.id/2021/01/ 27/lansia-di-atas-10-persenpopulasi-penduduk-sulut-menua/

Darmojo, \& Martono. (2018). Buku Ajar Geritrik (3 ed.). Jakarta: FK UI.

DEPKES RI. (2015). Pedoman Pengelolaan Kegiatan Kesehatan di Kelompok Usia. Jakarta: Departemen Kesehatan RI.

Erdayanti, S., \& Kartinah. (2016). Hubungan Tingkat Pengetahuan Lansia Dengan Perilaku Lansia Dalam Pemenuhan Personal Hygiene Di Panti Wreda Darma Bakti Pajang Surakarta. Retrieved Februari 15, 2020, from

https://publikasiilmiah.ums.ac.id /bitstream/handle/11617/3648/SI LIS\%20ERDHAYANTI\%20$\% 20 \mathrm{KARTINAH} \% 20 \mathrm{Fix} \% 20 \mathrm{bg}$ t.pdf? sequence $=1 \&$ is Allowed $=\mathrm{y}$
Hardono, Tohiria, S., Wijayanto, W. P., \& Sutrisno. (2019). FaktorFaktor Yang Mempengaruhi Personal Gygiene Pada Lansia. Wellness and Healthy Magazine, 1(1), 29-40.

Iswantiah. (2016). Personal Hygiene Konsep, Proses dan Aplikasi Dalam Peraktik Keperawtan (1 ed.). Yogyakarta: Graha Ilmu.

KEMKES RI. (2019). jumlah Penduduk Lanjut Usia Meningkat. Retrieved Februari 12, 2020, from http://www.depkes.go.id

Mubarak, Iqbal, W., \& Chayatin, N. (2017). Kebutuhan Dasar Manusia (1 ed.). Jakarta: EGC.

Notoatmodjo, S. (2014). Promosi Kesehatan dan Perilaku Kesehatan (2 ed.). Jakarta: Rineka Cipta.

Nursalam. (2016). Metodologi Penelitian Ilmu Keperawatan (1 ed.). Jakarta: Salemba Medika.

Ranandika, I., Sukraandini, N., \& Puspita Yanti, N. G. (2020). Pengalaman Lansia dalam Melakukan Personal Hygiene di Lingkungan Banjar Lebih Duur Kaje Gianyar. Jurnal Akademia Baiturrahim Jambi, 9(1), 115121.

Saryono, \& Widianti, A. T. (2015). Catatan Kuliah Kebutuhan Dasar Manusia (KMD) (1 ed.). Yogyakarta: Nuha Medika.

Sudarsih, S., \& Sandika, D. R. (2017). Hubungan Antara Dukungan Keluarga Dengan Kemandirian Lansia Dalam Pemenuhan 
Personal Hygiene di Desa Prajekan Kidul Bondowoso. Jurnal Keperawatan Bina Sehat, 14(2), 3-13.

Sudirman. (2018). Work Motivation and Achievement of Health Officers in Basic Program Public Health Center in Sojol District. Health Notions, 2(4), 450-452.

Trisani, A., Husodo, B. T., \& Kusumawati, A. (2017). Gabaran Praktik Personal Hygiene Pada lansia di panti Sosial Lanjut Usia Tresna Werdha Kota Semarang. Jurnal Kesehatan Masyarakat (JKM), 5(2), 180-187.

Wawan, \& Dewi. (2015). Teori dan Pengukuran: Pengetahuan, Sikap, dan Perilaku Manusia (1 ed.). Yogyakarta: Nuha Medika.
WHO. (2018). Global Report on Falls Prevention in Older Age. Retrieved Februari 12, 2020, from

http://www.who.int/violence_inj ury_prevention_/publication/oth er_injury/falls_prevention.pdf

Widanar, B. S. (2020, Oktober 13). Hubungan Tingkat Pengetahuan Lansia Dengan Perilaku Personal Hygiene Lansia di Dusun Krasakan Lumbungrejo Tempel Sleman Yogyakarta. Retrieved Juni 11, 2020, from http://digilib.unisayogya.ac.id/2 604/1/naskah\%20publikasi\%20S hinta\%20Widanar\%20B.\%2020 1310201055.pdf

Yuni. (2015). Personal Hygiene (1 ed.). Yogyakarta: Nuha Medika. 